\title{
LEARNING AND GROWTH
}

Boyan Jovanovic

Working Paper 5383

\section{NATIONAL BUREAU OF ECONOMIC RESEARCH 1050 Massachusetts Avenue \\ Cambridge, MA 02138 \\ December 1995}

I thank Will Baumol, Jess Benhabib, Fischer Black, Robin Cowan, Doug Dwyer, Paul Evans, Mark Gertler, Jeremy Greenwood, Jordi Gali, Chad Jones, Wolfgang Keller, Pete Klenow, Yaw Nyarko, Sergio Rebelo, and Noriyuki Yanagawa for comments, and the CV Starr Center of Applied Economics at New York University for technical assistance. This paper is part of NBER's research program in Productivity. Any opinions expressed are those of the author and not those of the National Bureau of Economic Research.

( $) 1995$ by Boyan Jovanovic. All rights reserved. Short sections of text, not to exceed two paragraphs, may be quoted without explicit permission provided that full credit, including $\odot$ notice, is given to the source. 


\section{LEARNING AND GROWTH}

\section{ABSTRACT}

In this survey, I discuss four sources of growth of knowledge: research, schooling, learning by doing, and training. In trying to disentangle what is important, I emphasize the following facts: (1) even the most advanced countries spend far more on adoption of existing technologies than on inventing new ones, and (2) countries frequently adopt "dominated" technologies. These facts provide a useful background for evaluating the different theories. They will also sharpen the point that it is important to distinguish between technology and human capital.

The conclusion is simply this: In generating world growth, the world's research outlays are an essential ingredient. But for most agents the decision determining growth is one of whether to adopt existing technologies. We have perhaps underemphasized this in our modeling so far. Moreover, the handful of models that I survey contains a bewildering array of diverse engines of growth, most of which are not based on any firm evidence.

\section{Boyan Jovanovic} Department of Economics University of Pennsylvania Philadelphia, PA 19104 and NBER 


\section{Introduction}

In this paper, I discuss four sources of growth of knowledge: research, schooling, learning by doing, and training. Presumably all four matter. In sorting out what is important, I shall emphasize the following two facts: (1) even the most advanced countries in the world spend far more on adoption of existing technologies than on inventing new ones, and (2) countries frequently adopt "dominated" technologies. These two facts provide a useful background for evaluating the different theories. They will also sharpen the point that it is important to distinguish between technology and human capital.

Technologies are laws of physics that are relevant to a particular way of producing something. These laws are described in blueprints. A blueprint, however, is an incomplete description of what it is useful to know about the technology at hand. ${ }^{1}$ Human capital is the knowledge of how to work the blueprints. One class of models does not distinguish technology from human capital. I will refer to this class as hybrid models.

One can distinguish technology from human capital, and one can assume that there are different types of technology, and/or different types of human capital. When a new technology appears on society's menu, unless the discovery was accidental, society pays an invention cost. Then there is the adoption cost. I shall focus on that component of the adoption cost to do with creating the human capital specific to the new technology. Essentially, this is the cost of training people -- in school or on the job -- to use the technology. Some of these costs are direct, others are in the form of foregone output. If there is no duplication in research, an invention cost needs to be incurred only once per new technology, whereas an adoption cost must be paid once per user. After this, there are just user costs.

When there are many types of technology, and many types of human capital, each somewhat specific to a technology, then it is not always optimal to pay the adoption costs in order to adopt the best technology. The class of models in which this is true, I shall call adoption models. There are three reasons why adoption models help us understand growth:

1 This incompleteness creates a role for training and learning by doing as ways of building up the specific human capital. Features of technologies that can be clearly explained in manuals will not call for training or experience. Other features of the optimal decision are specific to the situation at hand, to the nature of the factors of production, the raw materials, the location, the workspace, the specifications of the output, and so on. These, the workers will have to be taught, or they will have to infer it through trial and error. 
(i ) Most countries grow not by inventing, but by adopting inventions of others. ${ }^{2}$

(ii) Even in advanced countries, most of the costs of productivity growth are adoption costs: I will produce a rough estimate saying that in the U.S. adoption costs outweigh invention costs by 20 or 30 to 1 ! To use a new invention, I must first learn that it exists, what it means, how to make it useful, where to acquire all the complementary goods, and so on. Schooling and on-thejob training, as well as applied research, are all ways to prepare me for using any technology -old or new.

(iii) Adoption models can magnify the effects of any institutional feature that affects the incentive to adopt: small changes in adoption costs seem to have a big effect on growth for much the same reasons as tax rates on saving do in "Ak" models. These models say that growth is explained by adoption incentives, which we know vary widely among countries.

The paper proceeds as follows: I divide models into those that have scale effects, and "other models". The latter are divided into hybrid models and adoption models. I cover some of the models that I think are state of the art, and I apologize for omitting so many others. The plan of the body of the paper is:

\section{Models with scale effects}

3.A. Learning by doing in the capital goods sector: Arrow (1962)

3.B. Learning though research: Jones (1995b), Romer (1990)

3.C. Evidence on scale effects

3.D. Adoption costs as a limit to scale effects: Radner and Van Zandt (1992)

\section{Hybrid models}

4.A. Lucas (1988)

4.B. Prescott and Boyd (1987)

4.C. Parente and Prescott (1994)

4.D. Evidence on hybrid models

\section{Adoption models}

5.A. Parente (1994)

5.B. Lucas (1993)

5.C. Evidence on adoption models

2 Evenson (1984) finds that developing countries issue few patents. Even in developed countries, most technical change derives from transferred technology. See Baumol (1993, ch. 8). 


\section{Notation}

I shall try to use consistent notation throughout. This will make it easier to compare and contrast the engines of growth. I shall use the term agent to denote the decision unit which may be an individual, a plant or a firm. The agent's growth of knowledge can be written as:

$$
\frac{d s(t)}{d t}=F[s(t), a(t), S(t), A(t)]
$$

Here $s$ is the agent's state this period -- which may include things other that knowledge, $a$ is that agent's action; and $\mathbf{S}$ and $\mathbf{A}$ denote the "population" state and action, sometimes denominated as a population average, and sometimes denominated as a population total.

\section{Models with scale effects}

By a scale, I mean the number of agents in the economy, and their endowments. A scale effect is a change in some per-capita variables -- productivity level or productivity growth -- that comes about if we increase the economy's scale, while assuming that the distribution agents' actions and endowments is unchanged. ${ }^{3}$ The first two models assume an exogenous and fixed labor quality, so in a sense they have no human capital. They do have different types of technologies -- an ascending ladder. As formulated, they both have scale effects.

3.A. Learning by doing in the capital goods sector: In Arrow (1962), the engine is learningby-doing in the capital goods industry. Each producer is negligible, and learning is purely external in that the efficiency of each producer depends on the cumulative aggregate output of capital goods. There are no invention costs: the menu of technologies expands as a joint product with the supply of capital goods. Each new capital good is of superior quality to the previous ones. There are no adoption costs either, so that only the latest vintages of capital goods are ever purchased.

Let $s$ be the efficiency of a capital goods producer, and $a$ his output of capital goods. Aggregate output, $\mathbf{A}$, of capital goods is, by definition, the economy-wide gross investment in

3 As Young (1995) has recently emphasized, a scale effect is a feature of the technology, not necessarily a property of equilibrium, 
the capital-using industries. Specifically, let $s(t)$ be the reciprocal of Arrow's labor requirement of a vintage $t$ capital good. Then Arrow's eq.(8) -- his engine of growth -- reads

$$
s(t)=\delta\left(\int^{1} A(\tau) d \tau\right)^{\theta}
$$

To make this expression the equivalent of (1), we take the time derivative and obtain:

$$
\frac{\mathrm{ds}}{\mathrm{dt}}=\delta^{1 / \theta} \theta \mathrm{s}(\mathrm{t})^{-1 / \theta} \mathrm{A}(\mathrm{t})
$$

where $\theta>0$. At any time, capital goods of different ages are in use in production, but all capital goods producers are equally efficient, so that $\mathrm{s}=\mathbf{S}$.

Arrow's model has a scale effect in the levels: In a bigger economy, $\mathbf{A}$ would be bigger; doubling the level of $\mathbf{A}$ at all dates raises the level of $s(t)$ by a factor $2^{\theta}$. There is no scale effect in the growth rate:

$$
\frac{1}{s(t)} \frac{d s(t)}{d t}=\theta \frac{A(t)}{\int t A(\tau) d \tau}
$$

That is, doubling $\mathrm{A}$ at all dates leaves the growth rate unchanged.

The learning effects of $\mathbf{A}$ are like a public good -- management learning perhaps, produced collectively by all the capital goods firms jointly with their output of capital goods. One could remove the scale effect in the levels by letting $\mathbf{A}$ be output per worker in the capital goods sector. This changes the interpretation of $\mathbf{A}$ entirely, and it makes learning internal to the capital goods producers, changing their optimal decisions. This is more or less how Parente (1994) and Lucas (1993) model learning by doing.

3.B. Learning though research: In Jones (1995b), and Romer (1990) ${ }^{4}$, the engine is research. There are invention costs, but no adoption costs. The output of research is designs. Designs are sold by inventors to intermediate goods producers. In equilibrium, per-capita income grows at the same rate as the aggregate number of designs, $\mathbf{S}$.

Let $s$ be the cumulative number of designs invented by a researcher, and $a$ is the labor

4 See also Aghion and Howitt (1992, 1995), Grossman and Helpman (1991), and Kremer (1993). 
input that the researcher hires in his research firm. Then $\mathbf{S}$ is the cumulative number of designs invented by all researchers. Then (1) can be written as

$$
\frac{d s(t)}{d t}=\delta S(t)^{\gamma} a(t)
$$

Romer assumes $\gamma=1$.

Let $\mathrm{n}(\mathrm{t})$ denote the number of researchers. If the population is fixed, so is the equilibrium number of researchers, so that $\mathrm{n}(\mathrm{t})=\mathrm{n}$. Then and $d \mathbf{S} / d \mathbf{t}=\mathrm{n} d \mathrm{~s} / d \mathrm{t}$. The growth rate of $\mathrm{s}$ (And therefore also of $\mathbf{S}$ ) becomes

$$
\frac{1}{s(t)} \frac{\mathrm{ds}(\mathrm{t})}{\mathrm{dt}}=\delta \mathrm{nas} \mathrm{s}^{\gamma-1}
$$

So long as population is fixed and $\gamma<1$, the rate of growth goes to zero. If we once and for all double the population, and hence $\mathrm{n}$ too, we raise the growth rate at each date by a factor of 2 .

Now assume that population, and hence presumably $n$ grow at a constant rate $g_{n}$, the steady state growth rate of $s$ is equal to $g_{n} /(1-\gamma)$ when $\gamma<1$. There remains a scale effect in the levels, but there is no scale effect on the long-run growth rate.

3.C. Evidence: Arrow, Romer and Jones identify capital goods as the conduit of higher productivity, and in support of this assumption, recent price series (e.g. Gordon 1990) show capital goods falling in price relative to consumption goods. ${ }^{5}$ An open question is why capital goods enjoy faster progress. ${ }^{6}$ Moreover, the research model certainly gets support from firm data -- firms that do R\&D issue more patents, and their productivity is higher. And basic research -- which is where the inventions presumably come from -- does seem to be associated

5 In Rebelo (1991), the capital goods sector is also the engine of growth. Capital can reproduce itself with constant returns (the " $A k$ " feature) and there is (contrary to evidence) no technical change in that sector. The $A k$ structure is more appealing when one thinks of $k$ as including physical and human capital (as Black (1995) does), but it still does not exhibit technical change, unless there are external effects (so that instead of $A k$, one assumes $\mathrm{A}(\mathbf{k}) k$ ).

6 Cooley, et al (1995) say that this is because capital goods are more human capital intensive, but Klenow (1995) finds that sectors that enjoy faster TFP growth do not hire a disproportionate number of nonproduction workers. 
with high rates of productivity growth at the firm level (Griliches, 1986).

What about scale effects? They get modest support in time series and cross section data. (a) Time series evidence: As Jones (1995 a, b) notes, the world's productivity growth hasn't risen over this century. On the other hand, Kremer (1993, sec. 4B) argues that the scale effect in (4) helps explain some long run historical patterns. In particular, the growth rate of the world's per capita incomes is higher now than in earlier times when the world was more sparsely populated. A nice case study by Sokoloff (1988) showed that when effective market size grew in some U.S. regions because of an expansion of the canal system, this was followed by a rise in patenting activity in these areas.

(b) Cross section evidence: If we measure $\mathrm{n}$ and $\mathrm{s}$ at the economy wide level, we would resoundingly reject (4), because big economies do not grow faster than little ones. Nor are bigger economies wealthier per capita -- Backus et al () fail to find even level effects of economy size (although they find some effects of level effects of the size of countries' manufacturing sectors). At any rate, such tests are not obviously the correct way to look for scale effects, because they ignore the obvious fact that technologies cross borders. In terms of (1), we know that $\mathbf{S}$ must include some measure of foreign knowledge, and $\mathbf{A}$ must include something about foreign actions -- e.g., do they trade with us? This is precisely how Coe et al (1995) and Keller (1995) proceed, extending the methodology Griliches (1979) proposed for analyzing the productivity growth of firms. They assume that research capital stocks are distributed lags of total research outlays, not of per capita spending, and so these capital stocks have the dimensions of na in (4). So, augmented in this way, the research engine seems to fit the facts at the country level reasonably well.

We should expect to see some scale effects, since research, as expressed in (3) or (4), is surely essential in generating at least some of the outward movement of the world's knowledge frontier. And even when the world's knowledge frontier moves outward because of accidental discovery (which absorbs no resources) we expect a scale effect of the sort contained in (3). But, as Baumol (1993) argues persuasively, and as I will argue below, the lion's share the costs that the world incurs to raise its technological efficiency seems to be in the form of adoption costs, so that any scale effects that derive from invention should be small. Certainly this is so for the LDC's, and for all but a few developed countries.

How big a scale effect must we have in a research-based model? Young (1995) has emphasized that as the economy grows, we may see more duplication in research, and that this is one limit on scale effects. Here, I want to emphasize a different limit on scale effects of research -- the adoption cost. This is what I do in the next subsection. 
3.D. Adoption costs as a limit to research-based scale effects: One way to minimize scale effects is to assume that there is an adoption cost for each new technology, proportional to the number of workers that use it. What I am about to present is really a caricature of an argument made by Radner and Van Zandt (1992) who point out that more information can actually be harmful because the assimilation costs can outweigh the benefits! They argue that the costs of processing information acts to limit the size of organizations and the span of control.

To simplify, assume no physical capital, and that ideas are not embodied in machines.

Let $\mathrm{Y}$ denote the output of final goods, and $\mathrm{A}$ the number of ideas. The model is static, and production of $\mathrm{A}$ and $\mathrm{Y}$ is instantaneous, and given by the production functions

$$
\mathrm{Y}=\mathrm{AL}_{\mathrm{Y}}, \quad \text { and } \quad \mathrm{A}=\eta \mathrm{L}_{\mathrm{A}}
$$

where $L_{Y}+L_{A}=L$.

The scale of the economy is measured by $\mathrm{L}$. The only decision is how much labor to allocate to the research and the final goods sector. Let these allocations be given by

$$
\mathrm{L}_{\mathrm{A}}=\theta \mathrm{L} \quad \text { and } \quad \mathrm{L}_{\mathrm{Y}}=(1-\theta) \mathrm{L}
$$

We are interested in what happens to per capita income if we keep the distribution of decisions fixed (which here means a constant $\theta$ ) and let the scale of the economy increase. If there are no adoption costs, this model clearly has a scale effect on the level of per-capita income because

$$
\frac{\mathrm{Y}}{\mathrm{L}}=\eta \theta(1-\theta) \mathrm{L}
$$

So, if we double the scale of the economy, we double per-capita income.

Let us now show how the presence of adoption costs can remove the scale effect entirely. Assume that workers must learn how to use the ideas. Suppose that each worker must familiarize himself with a fraction $m$ of the ideas, and that the time it takes a worker to familiarize himself with an idea is $\tau$. Since there are $L_{Y}$ workers in the manufacturing sector, the total time cost of learning the ideas is

$$
\operatorname{m\tau AL} L_{Y}=\operatorname{m\tau } \eta \theta(1-\theta) L^{2} .
$$


This means that the effective time allocation in manufacturing is

$$
\mathrm{L}_{\mathrm{Y}}(1-\mathrm{m} \tau \mathrm{A})=(1-\mathrm{m} \tau \eta \mathrm{L})(1-\theta) \mathrm{L}
$$

so that now, per-capita output is

$$
\frac{\mathrm{Y}}{\mathrm{L}}=(1-\mathrm{m} \tau \eta \theta \mathrm{L})(1-\theta) \eta \theta \mathrm{L}
$$

Output can not be positive unless $\eta \theta \mathrm{L}<1 / \mathrm{m} \tau$, from which we find that

$$
\frac{Y}{L} \leq \frac{1-\theta}{m \tau}
$$

There is therefore an absolute upper bound to the level benefits of scale.

\section{Hybrid models}

In this section we turn to models that do not distinguish technology from human capital. Moreover, they do not distinguish types of knowledge, and so there is no distinction between invention and adoption. But since there are no scale effects in these models, they make sense only if adoption costs are the primary expense concerning the growth of knowledge.

4.A. In Lucas (1988), knowledge grows because time is taken from other uses and put into the accumulation of knowledge. Unlike Arrow's model there is no jointness in production. $s$ is a worker's knowledge, and $a$ is the fraction of the worker's time spent learning, and (1) reads

$$
\frac{\mathrm{ds}(\mathrm{t})}{\mathrm{dt}}=\delta \mathrm{a}(\mathrm{t}) \mathrm{s}(\mathrm{t})
$$

This formulation, first proposed by Ben-Porath (1967), can be termed "learning or doing", because only a fraction 1 - $a$ of time can be devoted to production. For later purposes, note that the costs of growth of $s$ are convex in the consumption good: because of diminishing marginal productivity of labor in the consumption goods sector, raising $a$ is more and more costly. 
In eq. (2.5) of Lucas (1993), (5) is modified to allow for spillovers:

$$
\frac{d s(t)}{d t}=\delta a(t) s(t)^{1-\theta} S(t)^{\theta}
$$

where $\mathbf{S}$ is average knowledge. ${ }^{7}$

4.B. Prescott and Boyd (1987) replace the infinite-lived agent by an overlapping generations. A worker is trained by the firm. The inputs are the knowledge per older worker $\mathbf{S}$, and time forgone, which, unlike Lucas (1988), Prescott and Boyd express in units of foregone output, which depends on the time allocation of young and old workers, respectively $a$ and $\mathbf{A}$, and on the knowledge per older worker, $\mathbf{S}$. This is necessarily a discrete time setup, in which we write $s^{\prime}$ for the knowledge bestowed to the young workers. Then (1) can be written as

$$
\mathbf{s}^{\prime}=\mathbf{S f}(\mathrm{a}, \mathbf{A})
$$

The growth factor, $f(a, A)$, depends on the actions of the old and young members of the firm. The formulation has constant returns to scale, so that small firms train and produce as easily as large firms. Implicitly, therefore, the costs of productivity improvement are proportional to the number of workers, and implicitly, therefore these are adoption - type costs -- such as training learning by doing at the level of the worker. The knowledge is entirely firm-specific; there are no spillovers from other firms. ${ }^{8}$

4.C. Parente and Prescott (1994) interpret $s$ as the efficiency of a firm, and $a$ as that firm's cost-reduction spending. and so expertise can be thought of as "business capital". But since the number of workers per firm is exogenous, one can think of the workers as the users, and of the adoption cost as a training expense in firm-specific skills; these skills can not be used in any other firm. Knowledge spills over from abroad. Thus $\mathbf{S}$ stands for world knowledge, the time path of which is exogenously given. They write (1) as

$$
\frac{\mathrm{ds}(\mathrm{t})}{\mathrm{dt}}=\delta\left(\frac{\mathrm{s}}{\mathrm{s}}\right)^{\alpha} \mathrm{a}
$$

7 Note that (6) is not part of Lucas's adoption model described in section 5 of this paper.

8 Related models are Chari and Hopenhayn (1991) and Kremer and Thomson (1994). 
Since $\alpha>0$, the returns to $a$ are higher for a backward economy. In contrast to Parente (1994), the cost to adjusting a technology is convex: to close the gap between a countries technology and the frontier by $1 / 2$ is more than twice as cheap as closing it fully. This convexity implies a convergence to the frontier productivity level. Presumably $\alpha$ depends on a country's degree of openness. But further microfoundations are needed for both $\delta$ and $\alpha$.

4.D. Evidence on hybrid models: The hybrid model is the only one that has been confronted with evidence in anything like a systematic way, and this is a point in its favor. However, I will focus here on a couple of ways that the model fails: (a) Marginal products of capital are implied to be too high in developing countries relative to developed ones, and (b) there is evidence that the assumption that we can add up efficiency units of labor is not a good one.

At the outset, one should note that we still do not have reliable estimates of even how workers learn on the job as a function of training, learning and so on. There are two reasons for this. First, on-the-job training is not observed, and is often inferred by assuming that it is chosen optimally. And second, vintage effects are hard to control for because observations of a worker are not, typically, well matched with the vintage or quality of the technology that he works on. ${ }^{9}$

On to evidence from aggregate data. Lucas (1990), in asking why inequality among countries persists in the face of apparent mobility of physical capital, argues that labor quality in poor countries is low -- so low, that the marginal product of capital in the rich and poor countries is the same. Lucas used some old estimates of Anne Kruger's to pin down the human capital level in India relative to that of the U.S. For his argument to work, there has to be a sizeable externality in labor quality -- i.e., in knowledge per head. The evidence, however, is not as favorable as Lucas's estimates suggest. He overestimates spillovers of knowledge when he attributes all the growth of the Solow residual to the growth of domestic knowledge. This is because, presumably, foreign knowledge matters as well. For example, using a somewhat different structure, Eaton and Kortum come up with the findings summarized in the table below. Clearly, one can not think of knowledge creation as taking place in a closed economy, unless that economy is the entire world, or at least the entire developed world:

9 The state of the art still seems to be Brown (1976), Haley (1976), and Heckman (1976). The production functions they specify differ, as do their parameter estimates, and conclusions. 
Eaton and Kortum's (1995, table 5) Growth Decomposition

\begin{tabular}{|l|ccccc|}
\hline $\begin{array}{l}\text { Fraction of } \\
\text { productivity } \\
\text { growth in: }\end{array}$ & Germany & France & U.K. & Japan & U.S. \\
\hline Germany & 0.38 & 0.06 & 0.09 & 0.31 & 0.16 \\
France & 0.23 & 0.22 & 0.09 & 0.31 & 0.16 \\
U.K. & 0.24 & 0.05 & 0.30 & 0.29 & 0.12 \\
Japan & 0.16 & 0.03 & 0.06 & 0.65 & 0.09 \\
U.S. & 0.14 & 0.03 & 0.06 & 0.19 & 0.58 \\
\hline
\end{tabular}

Foreign knowledge can matter in two ways. First, it can enter the production equation. Let the production function for output be $\mathrm{Y}=\mathrm{AK}^{\beta} \mathrm{H}^{1-\beta_{\mathrm{S}}} \mathbf{S}^{\boldsymbol{\sigma}}$. Here $s$ and $\mathbf{S}$ mean the same thing as in (7). Then let $y=Y / H$, and $x=K / H$. Then

$$
\mathrm{y}=\mathrm{Ax}^{\mathrm{\beta}} \mathbf{s}^{\mathrm{r}} \mathbf{S}^{\mathrm{o}}
$$

and the residual is $\mathrm{As}^{\gamma} \mathbf{S}^{\boldsymbol{\sigma}}$, and Lucas fits it to $s$ alone. So his estimate of $\gamma$ is really an estimate of $\gamma+\sigma[\mathrm{d} \log (\mathbf{S}) / \mathrm{d} \log (s)]$. Since $s$ and $\mathbf{S}$ are highly correlated over long periods of time, $\mathrm{d} \log (\mathbf{S}) / \mathrm{d} \log (s)$ is close to unity, and so he is really estimating $\gamma+\boldsymbol{\sigma}$.

Keller (1995) and Coe et al (1995) offer indirect evidence on $\gamma$ and $\sigma$. Indirect, because they construct scale-based measures of $s$ and $\mathbf{S}{ }^{10}$ According to Keller, the point estimates of $\gamma$ $=0.18$, and $\sigma=0.12$ are the most reasonable. The true $\gamma$ is therefore possibly much less than Lucas's estimated 0.36 , and the implied cross-country disparity in the marginal product of capital much bigger -- see Lucas (1990), eq. (4). When $\gamma$ is small, the model does pretty badly

10 Note that scale effects are not necessary for there to be asymmetries related to countries' scale: The U.S. and Luxembourg are similarly developed, yet one can be sure that the average Luxembourg resident learns more from the U.S. than an American learns from Luxembourg. This could be due to two separate factors:

(I) The U.S. does more R\&D than Luxembourg, so that there is more knowledge in the U.S. -- a scale effect.

(ii) The share of Luxembourg's imports that come from the U.S. is far greater than the share if U.S.'s imports that come from Luxembourg -- an accounting relation, not a scale effect.

As I understand it, both (I) and (ii) work to create an asymmetry in the coefficients as calculated by Keller and by Coe et al. 
in terms of equalizing the marginal product of capital over countries, and the incentives for labor to migrate to rich countries go away. ${ }^{11}$

The second possibility is that, $\mathbf{S}$ may enter the accumulation equation for $s$, as in (6) or (8) (Benhabib and Spiegel (1995, table 5, esp. column 5), in a hybrid model, find evidence for .In this case Anne Kruger's procedure for calculating human capital stocks is not appropriate because it ignores the spillover. In fact, if, say, (6) were true, her procedure exaggerates cross country differentials in proportion to $\theta$, [and the Keller estimate suggests that $\theta \approx 0.4$ ] and this again reduces the power of Lucas's explanation [in which we would now be forced to set $\sigma=0$ in (9)].

A further difficulty with those hybrid models that add up efficiency units of labor is the following: from the work of Bartel and Lichtenberg (1987), Mincer and Higuchi (1988) and others it is by now clear that more educated and more skilled workers have a comparative advantage in the implementing new technology. A hybrid model that adds up efficiency units of labor is incapable of variations in the earnings of skilled workers relative to unskilled that seem to accompany variations in the growth rate. In contrast, Parente's adoption model easily explains the correlation between the growth rate and skill differentials.

\section{Adoption models}

These models (a) distinguish human capital from technology, and (b) distinguish different types of each. To the the old Johansen-Salter vintage capital model, they add vintage-specific training and experience of labor. This creates a tension (absent in, say, Arrow 1962 where every investor wants to buy the latest vintage capital equipment) in choosing between a familiar method, and switching to a better, but untried one. The adoption cost is in part implicit -- it is the output foregone because of the productivity drop following a switch. ${ }^{12}$

5.A. In Parente (1994), $s(\mathrm{t})=[\mathrm{n}(\mathrm{t}), \mathrm{h}(\mathrm{t})]$, where $\mathrm{n}(\mathrm{t})$ is an index of the currently used technological blueprint (the "status quo" grade), and $h \in[0,1]$ is the level of expertise on that grade. Output equals $n(t) h(t)$. The action $a(t) \geq 1$ is the size of the firm's technological upgrade. Then

11 But there are things besides human capital externalities that could lead to pressure for migration: a) better infrastructure, b) better schools, c) more specialized services, and d) more political freedom. a) and b) are public goods financed by the higher average income in rich countries, and a) and c) would mean immigrants would earn more in the U.S. than in their country of origin.

12 I will not discuss the excellent Chari-Hopenhayn model as it has exogenous growth. 


$$
n(t+d t)=a(t) n(t) .
$$

If $\mathrm{a}(\mathrm{t})=1$, the firm does not upgrade. In this case, he accumulates grade-specific human capital (i.e., $h^{\prime}>h$ ). But upgrading $(a>1)$ leads to a loss of expertise. The exact relation is:

$$
h(t+d t)= \begin{cases}h(t)+(\lambda[1-h(t)]) d t & \text { if } \quad a(t)=1 \\ h(t)-\kappa-\delta a(t) & \text { if } \quad a(t)>1\end{cases}
$$

where $\lambda>0$ measures the speed of learning a given technological grade $n, k>0$ is a fixed cost of upgrading (its presence ensures that upgrading will not happen continuously), and $\delta$ is a cost proportional to the size of the upgrade. When there is an upgrade, total adoption costs are $\kappa+\delta a(t)$. Of course, these costs do not matter as $\lambda$ gets large: any drop in human capital (resulting from an upgrade) is quickly restored, and $\mathrm{h}$ would revert to 1 almost immediately. So, for $\lambda$ large enough, the optimal thing to do is upgrade as fast as possible. The same holds true as $\kappa$ and $\delta$ go to zero.

5.B. Lucas's (1993) is much the same, except that $\mathrm{h}(\mathrm{t})$ can be any positive number, and the firm's output is $n(t) h(t)^{\alpha}$. Lucas has (11) as well, but instead of (12), he has (see his eq. 4.2 and 4.7)

$$
h(t+d t)= \begin{cases}h(t)+h(t)^{\alpha} d t & \text { if } \quad a=1 \\ \int_{-\infty}^{n(t+d t)} w[n(t+d t)-x] h(x) d x & \text { if } \quad a>1,\end{cases}
$$

where $w($.$) is a weighting function, and h(x)$ is the firm's productivity on technological grade $x$ $\leq \mathrm{n}^{\prime}$, with $\mathrm{h}(\mathrm{x})=0$ for $\mathrm{x} \in\left(\mathrm{n}, \mathrm{n}^{\prime}\right]$. This formulation is consistent with there being no knowledge spillovers among firms.

Lucas has a more general distributed lag for how nearby technologies are related in terms of human capital requirements, but Parente actually carries out an equilibrium analysis of the problem. Stokey (1991) and Young (1993) analyze similar structures. Parente and Lucas conclude that highlighting the adoption choice can produce large growth-rate differentials. This is most firmly established in Parente's figures $4-8$, in which small changes in tastes and 
especially in the adoption cost parameters $\lambda, \kappa$, and $\delta .{ }^{13}$ Also relevant is Lucas's (1993) exposition of the hybrid model and its inability to generate miracles and disasters for realistic parameters and policies.

Why do small changes in adoption incentives matter so much for growth? My intuition says that, just as in the Rebelo-type "Ak" model, costs of growth are linear in the growth rate, and not convex as they are in the hybrid models that we discussed. Consider (6); if we want $\mathrm{s}$ to grow at the rate $g$, say, we must give up $\delta^{-1} g$ units of effort in each period. But because of diminishing returns for effort in the output equation, each additional unit of effort costs more -costs of growth are convex, and so the response of growth is less to external stimuli in the hybrid models. Now consider (12), in which $a=1+g$, where $g$ is the growth rate of the blueprint quality. Suppose we constrain switches to be one per unit of time. Then the costs of growth are $(\kappa+\delta)+\delta g$, and they are linear in $g$.

But if this intuition is roughly correct, then it is clear that the size of the growth response to external stimuli does not have to be bigger in an adoption model than in a hybrid model. One can write down hybrid models in which costs of growth are linear, and Mulligan and Sala-IMartin (1993) have done so. One can also write down adoption models in which the costs of growth are convex [one would, in (12), simply change $\delta$ a to $\delta$ (a) and assume that the function $\delta($.$) is convex], and Cooley et al (1995) gave done so, with the result that the effects on the$ growth rate of changing the investment tax credit (their analog of Parente's $x$ ) is much smaller than in Parente's model. ${ }^{14}$ So, as always, we need to look at micro data for information on what restrictions are, in each class of models, reasonable.

As descriptions of world growth, or the growth of the world's technological leaders, the Parente and Lucas adoption models would need to be extended to treat the growth of the frontiers of knowledge -- the size of the technological menu. In Lucas's model, any upgrading speed is feasible. Parente restricts $h(t+d t)$ in (12) to be nonnegative, which restricts the feasible growth factors $a(t)$ to those satisfying $a(t) \leq[h(t)-k] / \delta$.

5.C. Evidence on adoption models: There are 3 types of evidence in favor of the adoption model. The first two deal with the importance of adoption costs -- evidence that $\lambda$ is small, or

13 Parente's unpublished results show that the big effects on growth remain when instead the unrealistically low value $\lambda=0.025$ assumed in the published version, the simulations are done using the value $\lambda=0.3$. In Lucas (1993), the parameter $\xi$ (which is the one most likely to depend on national policies and institutions) seems to have a big effect on the long run rate of growth as determined implicitly in (4.10).

14 I thank Jeremy Greenwood for sending me results from an earlier version of Cooley et al (1995). 
that $\mathrm{K}$ and $\delta$ are large. The last says that adoption costs have tended to vary a lot over time and space.

(I) Adoption costs swamp invention costs: The fraction of U.S. resources spent on invention are tiny compared to resources spent on adoption. Money spent on inventing new things should be listed under "basic research". So let us suppose that all of basic research is invention. In the U.S., R\&D spending is less than 3\%. Of this, less than one-fifth is spending on basic research, and so about one half of one percent of U.S. output goes on invention.

Now learning-based adoption costs. These include the cost of injecting the labor force with the skills necessary to work with the methods that have been invented. Such skills are learned in school and on the job. Mincer (1994) estimates that schooling costs are over $10 \%$ of GNP, and the bulk of what goes on in school is probably designed to inform us about the technologies that are on the menu of available options. Let's say that at least half of what goes on in school prepares us for work. ${ }^{15}$ Then Mincer also estimates that on-the job training and learning costs are about 3\% -- an underestimate in my opinion. To this, we add applied R\&D spending, which is another $2 \%$ of output. So, total adoption costs are at least $10 \%-15 \%$ of U.S. output. This rough calculation says that adoption costs outweigh invention costs roughly 20 or 30 to 1 . In LDC's the ratio must be astronomical.

(ii) Micro evidence that adoption costs are large: (a) Teece (1977) and Mansfield et al (1981) produce firm-level evidence that for many processes, the adoption costs of a single user (sometimes referred to as imitation costs) can be almost as large as the costs of invention. More generally, diffusion lags for new technologies are long, suggesting that some sort of sizeable adoption cost is at work.

(b) Plant-level data show evidence of periodic, lumpy retooling (Power, 1993).

(c) Dwyer (1994) shows that faster growing sectors show greater inter-plant dispersion of productivity, just what one would expect in Parente's model when the upgrading decision is not perfectly synchronized.

(d) Entry of new plants and firms is common to all manufacturing industries. This is true of firms at the two digit level (Dunne et al, 1988) and is true of plants at the four digit level in textile industries in Dwyer's data. Some of these are declining industries. This entry probably represents the adoption of new technologies of plants, reflecting, probably a high upgrading cost on the part of existing plants.

(e) Bakh and Gort (1993) produce plant-level evidence that productivity continues to rise

15 Some of the schooling teaches us to invent things too, but since only one or two percent of people end up doing research, this number is negligible $[\approx(0.10) \mathrm{X}(0.02)=0.002$ of GNP $]$. 
significantly, years after a plant has been built., and this suggests large foregone output costs to switching technologies. In Parente's terms, $\lambda$ is small, certainly less than 0.5 .

(f) Klenow (1993) discusses evidence that technological upgrading is accompanied by sizeable drops in productivity, which supports the vintage human capital model in general, and shows that $\kappa$ or $\delta$ or both are significant.

(g) The management science literature has hundreds of examples of sizeable learning-by doing gains -- see Yelle (1979) for a survey.

(iii) People invest in dominated technologies: Such investments are common. Let us say that technology $\mathrm{A}$ dominates technology $\mathrm{B}$ if, given equal (in)experience with $\mathrm{A}$ and $\mathrm{B}$, a firm would prefer $\mathrm{A}$ to $\mathrm{B}$ at all input and output prices. And let us say that $\mathrm{A}$ dominates $\mathrm{B}$ conditional on some price being given, if $\mathrm{A}$ is preferred to $\mathrm{B}$ no matter what the other prices happen to be. In this subsection I shall claim that in a wide variety of instances, people invest in (conditionally) dominated technologies because of accumulated vintage-specific human capital.

Here are some examples: The steam engine continued to be sold in substantial number by some U.S. railroads, long after the Diesel engine (which conditionally dominated at the then prevailing prices of steam and oil) was introduced in the U.S. in the early $1920 \mathrm{~s}$ s. ${ }^{16}$ New agricultural seeds, arguably a dominant technology, took a long time to replace older ones (Griliches, 1957). The effectiveness of extension services in inducing the switch strongly suggests that ignorance about how to manage the new seeds was a key deterrent to adoption. The FORTRAN programming language has been superseded, but programs continue to be written, and people continue to be trained in it. By 1890 , the steam ship had become more cost effective on long and short routes (Harley 1971, p. 227), and yet sailing ships continued to be built well into the 20th century. As the Boeing 707 airplane was being phased out of commercial use in the U.S. in the early 1980's, the largest market for it was foreign airlines, even though the 707 was dominated: at the then price of fuel in the U.S., it was inferior on grounds of fuel efficiency, noise, and baggage room. ${ }^{17}$. There are dozens of other examples. Most new technologies take years to spread to the majority of firms -- see Mansfield (1968, ch. 8). Since firms invest more or less continuously, their investment often flows into old technologies.

The existence of adoption delays and investments in old technology does not per se prove that the barrier is technology-specific human capital (as Lucas and Parente emphasize). For that, we need stronger evidence. But we must note that the vintage physical capital model without adoption costs (Johansen 1959, Salter 1960) does not explain why someone would invest in even

${ }^{16}$ Interstate Commerce Commission (1950), tables A-4, A-5.

17 Some (but not an overwhelming proportion) of the 707's were sold to OPEC countries for whom their fuel inefficiency did not matter. See Goolsbee (1995). 
a conditionally dominated technology: Having old equipment on hand will cause a firm to delay replacing it, but when it finally does so, the firm should invest in an undominated technology. Now if we add adoption costs in the form of sunk costs or gestation lags associated with the new technology, as Benhabib and Rusticchini (1991) do, the physical capital vintage model starts to look a lot like the Parente and Lucas models, since the sunk cost and gestation lags play the same role that training costs and learning periods do.

While vintage physical capital can not explain dominated investment, we should note that aside from vintage human capital, there are other explanations: (I) cheap labor induces poor countries to acquire old, labor intensive equipment that is not unconditionally dominated, (ii) trade restrictions, as Romer (1994) has emphasized, prevent the adoption of foreign equipment (iii) finance constraints may preclude investment in bulky and expensive new equipment, (iv) coordination problems to do with compatibility of machinery are severe in poor countries. ${ }^{18}$

(iv) Adoption costs vary among countries and over time. In most places, new technology is imported from abroad, restrictions on the operation of multinationals or joint ventures with a foreign partner will be quite important. Other legal and illegal historical instances of the suppressing of innovations, and other writings by economic historians discussed at length by Baumol (1993). In Parente's terms, such activities raise $\boldsymbol{\kappa}$ and $\delta$, with large predicted consequences for growth.

In some countries, skilled labor is scarce. Looking across countries, Benhabib and Spiegel (1994) find the level of education is a stimulus to growth. This fits in with the hypothesis that educated workers have a comparative advantage in implementing new technology. Parente's model naturally explains the phenomenon if skilled people have a higher $\lambda$, they optimally upgrade faster.

In some countries social mobility is restricted, and background is important for how talent is allocated to occupations. Galor and Tsiddon (1995) show that if able people have a comparative advantage in new technologies, a system that overemphasizes background and restricts mobility across occupations will reduce long-run growth. Since countries differ a lot in the latitude they allow to social mobility, this may be an important explanation of differential growth experience.

18 Frankel (1955, section 5), and Salter (1960, p.85) discuss the issue in railways, in weaving, in iron and steel manufacture, and elsewhere. When such "network externalities" are important, reliable maintenance and availability of spare parts can greatly affect productivity, as Pack (1987, p. 119) notes. Let output $Q$ depend on intermediates $X_{i}$ as follows: $Q=\min _{1}\left(X_{1}, X_{2}, \ldots, X_{n}\right)$, where $\mathrm{X}_{\mathrm{i}}=1$ with probability $\epsilon$, and 0 with probability $\epsilon$. So $\epsilon$ measures "unreliability". Then $E(Q)=(1-\epsilon)^{\mathrm{n}}$. So the effects of unreliability accumulate geometrically. See Matsuyama (1995) for more on this issue. 


\section{Conclusion}

The adoption models that I have described highlight the adoption margin as the critical one for growth, and in a specification like Parente's distorting this margin can greatly change the rate of growth. Why would adoption incentives differ among countries and over time? As it stands, the model can only answer this by focusing on initial conditions -- the existing profile of past investments.

Of course there is more to it than this -- tradition, institutions, politics, culture -- all of these influence not only adoption incentives in particular, but attitudes to work and interest in material rewards more generally. The adoption model says that to understand the way tradition and institutions affect growth, we must analyze how they affect the incentives, and the sheer ability to adopt and implement technology from abroad.

I have not mentioned exogenous growth models, which usually are the starting point of any survey of growth theory. The debate about the usefulness of the exogenous growth model will go on. Here I will mention two points that relate the exogenous growth model to the points that I have emphasized above. First and foremost, these models assume that technological adoption costs are zero -- two countries with the same level of education and the same level of physical capital will produce the same amount of output. There is no cost to accessing the world's frontier, no cost do adopting new technologies.

Second, the exogenous growth models imply than if countries have identical tastes and technologies, they should converge to the same level. But the evidence against unconditional convergence is overwhelming. Instead, there is a large empirical literature ${ }^{19}$ showing that one can find relatively rapid convergence to very different (and permanently different) steady states. Different steady states can be represented by country-specific "fixed effects", or by including some endogenous proxies for investment in human and physical capital, development of political and financial institutions, and so forth, on the right-hand side of a growth regression. Of course, fixed effects are unattractive if one is attempting to implement a complete theoretical model empirically. In practice, however, theoretical models abstract from all but the most crucial features of the environment that they seek to understand, and, moreover, attaching explicit names to some of the sources of cross-country heterogeneity is not hard; e.g., climate, topography, war, etc.

In the models that I do survey in this paper, there is, of course, room for fixed effects to represent unmodelled differences among countries. But more to the point, cross country regressions generally fail to recognize technological and factor market dependence adequately. Most economies are not closed, there is factor mobility between most countries, and in most

19 A recent contribution is Evans (1995). 
places, people can access the technological frontier at a cost. Every business must choose from the menu of technologies. Anybody can buy a pentium, and yet, not everyone owns one. We know technology adoption is endogenous and generally different everywhere. If we ignore this, I think we miss the story of growth and development. 


\section{References:}

Aghion, Philippe, and Peter Howitt, "A Model of Growth through Creative Destruction," Econometrica 60, no.2 (March 1992): 323 - 51.

Aghion, Philippe, and Peter Howitt, "Structural Aspects of the Growth Process, " Nuffield College, Oxford University, June 1995.

Arrow, Kenneth, "The Economic Implications of Learning by Doing," Review of Economic Studies 29 (June 1962):155 - 74.

Backus, David, Patrick Kehoe, and Timothy Kehoe, "In Search of Scale Effects in Trade and Growth," Journal of Economic Theory 58 (1992): 377 - 409.

Black, Fischer, Exploring General Equilibrium Cambridge, MA: MIT Press, 1995.

Bakh, Byong-Hyong and Michael Gort. 1993. "Decomposing Learning by Doing in New Plants." Journal of Political Economy 101, no. 4: 561 - 583.

Bartel, Anne, and Frank Lichtenberg, "The Comparative Advantage of Educated Workers in Implementing New Technology, "Review of Economics and Statistics 69 (February 1987): $1-11$

Baumol, William, Entrepreneurship, Management, and the Structure of Payoffs, Cambridge, MA: MIT Press, 1993.

Benhabib, Jess, and Aldo Rusticchini,"Vintage Capital, Investment, and Growth," Journal of Economic Theory 55 (1991): 323 - 339.

Benhabib, Jess, and Mark Spiegel, "The Role of Human Capital in Economic Development: Evidence from Aggregate Cross Country Data," Journal of Monetary Economics 34 (1994): $143-173$.

Ben-Porath, Yoram, "The Production of Human Capital, and the Life Cycle of Earnings," Journal of Political Economy 75, no.4 pt.1 (August 1967): 352 - 361.

Brown, Charles, "A Model of Optimal Human-Capital Accumulation and the Wages of Young High School Graduates," Journal of Political Economy 84, no.2 (April 1976): 299 - 316.

Chari, V.V., and Hugo Hopenhayn, "Vintage Human Capital," Journal of Political Economy 99, no.6 (December 1991): 1142-1165.

Coe, David, Elhanan Helpman, and Alexander Hoffmeister, "North-South R\&D Spillovers," NBER working paper no. 5048, March 1995.

Cooley, Thomas, Jeremy Greenwood, and Mehmet Yorukoglu, "The Replacement Problem," unpublished, University of Rochester, July 1995

Dunne, Timothy, Mark Roberts, and Larry Samuelson, "Patterns of Firm Entry and Exit in the US manufacturing Industries," Rand Journal of Economics 19, no. 41 (1988): 495 - 515.

Dwyer, Douglas, "Technology Locks, Creative Destruction, and Non-Convergence in Productivity Levels," unpublished paper, Columbia University, October 1994. 
Eaton, Jonathan, and Samuel Kortum, "International Patenting and Technology Diffusion," Boston University, May 1995.

Evans, Paul, "How to Estimate Growth Regressions Consistently," Ohio State University, August 1995.

Evenson, Robert, "International Invention: Implications for Technology Market Analysis, " in Zvi Griliches, ed., R\&D. Patents and Productivity, Chicago: University of Chicago Press, 1984.

Frankel, Marvin, "Obsolescence and Technical Change," American Economic Review 35, no. 3 (June 1955) 296 - 319.

Galor, Oded, and Daniel Tsiddon, "Technological Progress, Mobility, and Economic Growth," working paper \# 95 - 32, Brown University, August 1995.

Goolsbee, Austan, "Factor Prices and the Retirement of Capital Goods," unpublished, Graduate School of Business, University of Chicago, July 1995.

Gordon, Robert, The Measurement of Durable Goods Prices. NBER, Chicago, IL: University of Chicago Press, 1990.

Griliches, Zvi, "Hybrid Corn: An Exploration in the Economics of Technological Change," Econometrica 25, no. 4 (1957): $501-22$.

Griliches, Zvi, "Issues in Assessing the Contribution of Research and Development to Productivity Growth," Bell Journal of Economics 10 (Spring 1979): 92 - 116.

Griliches, Zvi, "Productivity, R\&D, and Basic Research at the Firm Level in the 1970's," American Economic Review 76, no. 1 (March 1986): 141 - 54.

Grossman, Gene, and Elhanan Helpman, "Quality Ladders and Product Cycles," Quarterly Journalof Economics 106 (1991): 557 - 586.

Haley, William, "Estimation of the Earnings Profile from Optimal Human Capital Accumulation," Econometrica 44, no.6 (November 1976): 1223 - 38.

Harley, Charles "The Shift from Sailing Ships to Steamships 1850 - 1890: A Study in Technological Change and its Diffusion," Essays on a Mature Economy: Britain After 1840, Donald McCloskey, ed., Princeton, NJ: Princeton University Press, 1971.

Heckman, James, "Estimates of a Human Capital Production Function Embedded in a Life-Cycle Model of Labor Supply," in Household Production and Consumption, Nestor Terleckyj editor, Conference on Income and Wealth vol. 139, New York; Columbia University Press (1976): 227 - 58.

Interstate Commerce Commission. Bureau of Transport Economics and Statistics. Study of Railroad Motive Power. Washington, Interstate Commerce Comm. 1950.

Johansen, Leif "Substitution versus Fixed Production Coefficients in the Theory of Economic Growth," Econometrica 27, no. 2 (April 1959): 157 - 176.

Jones, Charles, "Time Series Tests of Endogenous Growth Models, " Quarterly Journal 
of Economics (May 1995): 495 - 525. (1995a)

Jones, Charles, "R\&D-Based Models of Economic Growth," Journal of Political Economy 103, no. 4 (August 1995) (1995b).

Keller, Wolfgang, "International R\&D Spillover and Intersectoral Trade Flows: Do They Match?" Unpublished paper, Yale University, June 1995.

Klenow, Peter, "Learning Curves and the Cyclical Behavior of Manufacturing Industries," unpublished paper, Graduate School of Business, University of Chicago, September 1993.

Klenow, Peter, "Human Capital vs. Ideas: Industry Evidence on Growth Models," unpublished paper, Graduate School of Business, University of Chicago, March 1995.

Kremer, Michael and Jim Thomson, "Young Workers, Old Workers, and Convergence," NBER working paper \#4827, August 1994.

Lucas, Robert E., "On the Mechanics of Economic Development," Journal of Monetary Economics 22 (1988): 3-42.

Lucas, Robert E., "Why Doesn't Capital Flow from Rich to Poor Countries?" American Economic Review 80, no. 2 (Papers and Proceedings, May 1990): 92 - 6.

Lucas, Robert E., "Making a Miracle," Econometrica 61, no. 2 (March 1993): 251 -72.

Mansfield, Edwin, Mark Schwartz, and Samuel Wagner, "Imitation Costs and Patents: An Empirical Study," Economic Journal 91 (December 1981): 907-18.

Matsuyama, Kimonori, "Economic Development as Coordination Problems," discussion paper no. 1123, Northwestern University, April 1995.

Mincer, Jacob, "Investment in U.S. Education and Training, " NBER wp \# 4844 (November 1994)

Mincer, Jacob, and Yoshio Higuchi, "Wage Structures and Labor Turnover in the U.S. and Japan," Journal of the Japanese and International Economies, 2 (1988): 97 - 133

Mulligan, Casey, and Xavier Sala-I-Martin, "Transitional Dynamics in Two-Sector Models of Endogenous Growth," Quarterly Journal of Economics 108, no. 3 (August 1993): 739 774.

Pack, Howard, Productivity. Technology, and Industrial Development: A Case Study in Textiles, New York: Oxford University Press, 1987

Parente, Stephen, "Technology Adoption, Learning-by-Doing, and Economic Growth," Journal of Economic Theory 63, no.2 (August 1994): 346 - 69.

Parente, Stephen, and Edward Prescott, "Barriers to Technology Adoption and Development," Journal of Political Economy 102, no. 2 (April 1994): 298 - 321.

Power, Laura, "Causes and Consequences of Investment Spikes in U.S. Manufacturing Plants. " unpublished manuscript, University of Maryland (November 1993) 
Prescott, Edward, and John Boyd, "Dynamic Coalitions, Engines of Growth," American Economic Review, Papers and Proceedings 77, (May 1987): 63 - 67.

Radner, Roy, and Tim Van Zandt, "Information Processing in Firms and Returns to Scale," Annales d'Economie et de Statistique 25/26 (1992): 265 - 298.

Rebelo, Sergio. 1991."Long-Run Policy Analysis and Long Run Growth," Journal of Political Economy 99, no.3, pp. $500-21$.

Romer, Paul, "Endogenous Technological Change," Journal of Political Economy 98, no. 5, pt.2 (October 1990): S71 - S102.

Romer, Paul, "New Goods, Old Theory, and the Welfare Costs of Trade Restrictions," Journal of Development Economics 43 (1994): 5 - 38.

Salter, W.E.G., Productivity and Technical Change, New York: Cambridge University Press, 1960.

Schmitz, James, "Early Progress on the Problem of Economic Development"', Federal Reserve Bank of Minneapolis Quarterly Review (Spring 1993): 17 - 35.

Sokoloff, Kenneth L., "Inventive Activity in Early Industrial America: Evidence from Patent Records, 1790-1846", Journal of Economic History, 48 (Dec 1988): 813 - 50

Stokey, Nancy, "Human Capital, Product Quality, and Growth," Quarterly Journal of Economics 106 (1991): 587 - 616.

Symposium on the New Growth Theory, Journal of Economic Perspectives 8, no. 1 (Winter 1994): 3 - 72.

Teece, David, "Technology Transfer by Multinational Firms: The Resource Cost of Transferring Technological Knowhow," Economic Journal 87 (June 1977): 242 - 61.

Yelle, Louis, "The Learning Curve: Historical Review and Comprehensive Survey," Decision Sciences 10 (1979): 302 - 328.

Young, Alwyn, "Invention and Bounded Learning by Doing," Journal of Political Economy 101, no. 3 (June 1993): 443-72.

Young, Alwyn, "Growth without Scale Effects," NBER working paper no. 5211, August 1995. 